\title{
Discusiones sobre el control patronal
}

\author{
Discussões sobre controle do empregador \\ Discussions about employer control
}

Claudio Katz ${ }^{1}$

\begin{abstract}
Resumen
El artículo evalúa las principales tesis y críticas de la teoría del control patronal a la luz del desenvolvimiento actual del capitalismo. Analiza la consistencia de ese enfoque con la teoría marxista y contrasta el aporte de Braverman con problemas de la visión neoclásica y la Teoría de la Regulación. El texto también revisa el alcance asignado al concepto de taylorismo en función de la segmentación e intelectualización actual del trabajo. Estudia en qué sentido Braverman privilegió la problemática de la resistencia al análisis del consentimiento e indaga cómo abordó la relación entre los procesos de trabajo y valorización. También se señalan aciertos, en la medición de las calificaciones por el grado de dominio en la comprensión de la tarea realizada. Pero se destaca la problemática relación de los pronósticos de descalificación absoluta con el concepto de miseria creciente. Se subrayan las implicancias políticas de esta tesis. El artículo pondera del enfoque totalizador de Braverman y su énfasis en la centralidad y no el fin del trabajo. Destaca como su mirada permite comprender el trasfondo confiscatorio de la precarización actual del empleo.
\end{abstract}

Palabras-clave: Marxismo. Proceso de Trabajo. Taylorismo. Capitalism.

\section{Resumo}

O artigo avalia as principais teses da teoria e crítica de empregadores, tendo em conta o desenvolvimento atual de controle capitalismo. Analisar a consistência desta abordagem com a teoria marxista e contrasta a contribuição de Braverman problemas de visão e teoria neoclássica da regulação. O texto também analisa o alcance do conceito de taylorismo atribuído com base na segmentação atual e intelectualização do trabalho. Descubra o caminho que o problema da análise de resistência Braverman privilegiada e investiga como consentimento abordou a relação entre os processos de trabalho e recuperação. Também são relatados sucessos na medição marcas para o grau de domínio no entendimento da tarefa. Mas a relação problemática das previsões de desqualificação absoluta com o conceito de miséria crescente stands. As implicações políticas desta tese estão sublinhadas. $O$ artigo reflete sobre a abordagem holística de Braverman e sua ênfase na centralidade e não o fim do trabalho. Seus olhos fora como pano de fundo para a compreensão do caráter confiscatório emprego precário atual.

Palavras-chave: Marxismo. Processo de Trabalho. Taylorismo. Capitalismo.

\begin{abstract}
The article evaluates the main theses of the theory and criticism of employers in light of current development of capitalism control. Analyze the consistency of this approach with Marxist theory and contrasts the contribution of Braverman impaired vision and neoclassical theory of regulation. The text also reviews the scope of the concept of

Texto enviado en 27 de enero 2014 y aprobado para publicación en 7 de noviembre 2014.

DOI: http://dx.doi.org/10.1590/1679-395139682

Doctor en Geografía; Profesor de Economía en el Departamento de Historia de la Facultad de Filosofía y Letras de la Universidad de Buenos Aires; Investigador del Consejo Nacional de Ciencia y Tecnología. Dirección: Salguero, 20448 P. Buenos Aires, Argentina. E-mail: claudiokatz1@gmail.com
\end{abstract}


Taylorism assigned based on the current segmentation and intellectualization of labor. Find out which way the problem of privileged Braverman resistance analysis and investigates how consent addressed the relationship between work and recovery processes. Successes are also reported in measuring marks for the degree of dominance in the understanding of the task. But the problematic relationship of absolute disqualification forecasts with the concept of increasing misery stands. The political implications of this thesis are underlined. The article ponders the holistic approach of Braverman and his emphasis on the centrality and not the end of work. His eyes out as confiscatory background for understanding the current precarious employment.

Keywords: Marxism. Work Process. Taylorism. Capitalism.

La teoría desarrollada por el estudioso norteamericano Harry Braverman constituye una referencia insoslayable para el análisis contemporáneo del proceso de trabajo. Revisar su concepción desde el propio enfoque del marxismo, a cuarenta años de la publicación de Trabajo y Capital Monopolista permite evaluar aciertos, aportes y problemas de una obra que revolucionó la sociología laboral y que hemos debatido en distintos eventos ${ }^{2}$.

\section{El Significado del Taylorismo}

Braverman describió cómo el trabajo humano se diferencia de los actos instintivos de los animales por su carácter premeditado y consciente. Pero destacó también que en el proceso laboral la concepción puede fracturarse de la realización de las tareas, permitiendo que la actividad concebida por un individuo sea concretada por otro. Esta posibilidad de comandar el trabajo ajeno, permite establecer una relación de explotación a favor de los beneficiados de esa ruptura (BRAVERMAN, 1980).

Durante la esclavitud y el feudalismo las clases dominantes recurrían explícitamente a la fuerza para explotar a los oprimidos. Pero bajo el capitalismo esa coerción física directa ha sido reemplazada por una compulsión económica. Para subsistir, los asalariados deben a vender su fuerza de trabajo a un valor inferior al incorporado durante la jornada laboral.

Pero esta apropiación de plusvalía exige el control capitalista del proceso de trabajo. Braverman estudió las formas de esa dominación, destacando que los patrones necesitan supervisar cuidadosamente el uso de la capacidad muscular y cerebral de los operarios.

El teórico estadounidense describió la historia de ese control (proletarización de los campesinos y expropiación de los conocimientos artesanales) durante el tránsito de la manufactura a la gran industria. Recordó que el capitalismo se conformó como sistema, privando a los asalariados de los medios de subsistencia y capturando su manejo del saber técnico. La división del trabajo se desenvolvió para asegurar esta disciplina de los operarios.

Pero el hito central de este proceso fue la generalización del taylorismo durante las primeras décadas del siglo XX. Este modelo impuso el control patronal cómo norma general de la actividad laboral. Instauró una "organización científica del trabajo", basada en la cadena de montaje, el cronómetro, la parcelación de las tareas y la meticulosa adaptación del esfuerzo laboral a los ritmos de producción.

Taylor nunca ocultó su intención de sofocar la resistencia de los obreros, reduciendo su comprensión de las tareas realizadas. Estableció un sistema que dislocó las especialidades y concentró los conocimientos en la gerencia. Para potenciar la valorización del capital brutalizó la fuerza de trabajo.

${ }^{2}$ Hemos abordado previamente el tema en un trabajo anterior que fue la primera versión de este trabajo: Katz, Claudio, 2000. 
Braverman resaltó la naturaleza capitalista de este esquema laboral, que transforma al trabajador en una pieza intercambiable del proceso productivo. El taylorismo se expandió primero en la industria, penetró luego en las oficinas y se extendió finalmente al comercio y los servicios.

Los propios supervisores quedaron atrapados por un sistema que colonizó a todas las profesiones. Incluso viejas actividades personalizadas (como el trabajo de la secretaria) quedaron sometidas a la monotonía fragmentaria del taylorismo.

\section{Evaluación Histórica}

Las tesis de Braverman incentivaron intensos debates historiográficos sobre el origen del control patronal. El trabajo domiciliario y la remuneración por pieza fueron esenciales en Gran Bretaña para consumar la expropiación de los conocimientos obreros. Mediante una acentuada división del trabajo se incrementó la vigilancia sobre operarios agrupados en fábricas, que fueron edificadas junto a las cárceles y los reformatorios.

Este dominio patronal perdió terreno durante la segunda mitad del siglo XIX con el afianzamiento de la organización sindical y la reducción de la jornada de trabajo. En ese momento comenzó un proceso inverso de reapropiación parcial del control laboral por parte de los trabajadores. Esta reconquista se extendió, cuándo la presión competitiva obligó a los empresarios a diversificar sus formas de administración (MARGLIN, 1977; LAZONICK, ZEITLIN, ELBAUM et al., 1979)

También en Estados Unidos la organización del trabajo tuvo una evolución contradictoria. Taylor averiguó los secretos de la fabricación, calculó los tiempos (y movimientos) de los operarios y estableció los ritmos de producción. Pero una vez procesado el impacto inicial de este atropello, los trabajadores limitaron parcialmente la tiranía de la cadena de montaje.

La "organización científica del trabajo" buscó contrarrestar la fuerza social de los asalariados, en un país con alto crecimiento y gran movilidad laboral. Pero ese éxito patronal quedó erosionado con la conquista de los convenios colectivos y la legalización de los sindicatos.

El taylorismo acompañó también la expansión de las grandes corporaciones, que desplazaron al inventor independiente y subordinaron a los ingenieros a la empresa. En ese período se impuso la estandarización de la ciencia y el afianzamiento de una ideología patronal en la enseñanza. Pero también este curso enfrentó serias resistencias.

La implantación del nuevo modelo coincidió, además, con las innovaciones que dotaron a la cadena de montaje del flujo regular de energía, requerido para la producción ininterrumpida. Se consumó una también una reorganización administrativa para acelerar los tiempos de fabricación y circulación de las mercancías. La propia gerencia terminó absorbiendo el taylorismo y sólo un reducido grupo de directores mantuvo la unidad de concepción y realización del conjunto de la actividad (MONTGOMERY, 1985; GORDON, EDWARDS y REICH, 1985; NOBLE, 1987; CHANDLER, 1987).

La "organización científica del trabajo" nunca impuso totalmente la disciplina del cronómetro, pero dejó formas perdurables de administración empresaria. ¿Estas modalidades subsisten o se han extinguido?

\section{Confirmaciones Parciales}

La teoría del control patronal contribuye a explicar muchos rasgos de la ofensiva neoliberal de las últimas décadas. Ese atropello ha buscado recuperar la dominación capitalista del proceso de trabajo, que fue 
desafiada por las rebeliones obreras de los años 60 y 70. La política de flexibilización laboral ha sido una explícita respuesta a la lucha de ese período.

Mediante la reducción de los salarios y la masificación del desempleo, los trabajadores fueron colocados a la defensiva. Las clases dominantes recurrieron a la cobertura ideológica de un supuesto imperativo técnico, para recomponer el control patronal.

A través de la rotación de tareas se restableció el manejo gerencial de los tiempos y movimientos, con la polivalencia se multiplicaron las obligaciones del trabajador y con los círculos de calidad se extendieron las responsabilidades en el cumplimiento de las metas de producción. Los grupos autónomos han servido para complementar esta disciplina, con exigencias de cuidado de la calidad y resolución de los desperfectos.

El trabajo flexibilizado incrementó, además, la presión por disminuir los tiempos muertos y reducir las existencias. Con el "just in time" reapareció la vieja obsesión taylorista por acelerar el proceso de fabricación. Esta reorganización ha sido combinada con mayor subcontratación y empleo de tiempo parcial, para aprovechar al máximo la capacidad muscular y cerebral de los asalariados.

La intensificación del trabajo se ha verificado en las últimas dos décadas, en todos los países y sectores. En Estados Unidos ha sido muy visible la ampliación de la jornada de trabajo, el aumento del esfuerzo laboral y la reducción del tiempo de recreación. La publicitada gratificación de algunos trabajos sólo involucra a un sector minoritario de las empresas.

En Japón rige una agobiante sobredosis laboral, que se agravó durante el estancamiento de las últimas décadas. En este contexto quedó socavada la estabilidad del empleo y fueron afectadas las viejas atribuciones de los trabajadores calificados. También en los países europeos -que mantuvieron conquistas laborales nunca alcanzadas en otras regiones- se produjo una dramática progresión del empleo a tiempo parcial. Esta opresión contrasta con imágenes de trabajo "posfordista consensuado" que ocultan la persistente continuidad del sufrimiento laboral.

En las naciones periféricas la degradación ha incluido la brutalidad de las maquiladoras centroamericanas y el sofocante ritmo de las líneas de montaje del sudeste asiático. Las corporaciones lucran con la localización de plantas, en las zonas de mayor baratura de la fuerza de trabajo. La amenaza de trasladar la fábrica a la periferia se ha convertido, además, en un instrumento de disuasión de las protestas sociales en los países desarrollados (HUNTER, 2000; MILKMAN, 1997; FREYSSENET y KOICHI; 1998; BARRIER LYNN, 1983; LINHART, 1997; DEJOURS, 1998; LIPIETZ, 1992, cap. 2, 4, 5).

Este cuadro de intensificación del trabajo ilustra la subsistencia de muchos rasgos del taylorismo, tanto en la acepción superficial del término (trabajo rutinario), cómo en el sentido de control patronal que propuso Braverman. Muchos teóricos del "pos-taylorismo" ignoran esta persistencia.

El control patronal se mantiene en la agenda de la clase capitalista. Los gerentes cambiaron el lenguaje pero no sus objetivos. Aunque hablen de conocimiento y comunicación, pero jerarquizan el mantenimiento de la disciplina en la empresa.

El taylorismo subsiste, además, como instrumento de ruptura de las relaciones que establecen informalmente los trabajadores para reducir la presión gerencial. Las nuevas tecnologías de la información son particularmente utilizadas con ese propósito (DRUCKER, 1992; DINA, 1988; SHAIKEN, 1981).

Pero las tesis de Braverman enfrentan dificultades para explicar por qué razón los viejos criterios tayloristas tienden a ser mixturados con nuevas técnicas de administración. La línea de montaje y las tareas prefijadas son combinadas con cierta delegación del poder de decisión. La tiranía del cronómetro prevalece en los sectores que requieren velocidad de fabricación, producción estandarizada y gasto muscular intensivo. Pero en las actividades que exigen mayor calidad y especialización se refuerza el papel de nuevos procedimientos. 
El control patronal ha enfrentado un serio límite para gestionar tareas complejas. Con simple división de competencias y separación de actividades no se puede involucrar al trabajador en las labores, que exigen mayor atención (CORIAT, 1992; PERRIN y CANARON, 1988).

\section{Los Problemas de la Teoría}

La diversificación, la intelectualización y la dualización del trabajo que aparecieron en las últimas décadas, obligan a replantear la teoría del control patronal. El enfoque de Braverman supone que los capitalistas refuerzan su dominio, a medida que el trabajo se uniforma.

Esta tendencia efectivamente se verifica junto a la expansión del proletariado industrial en la periferia o el ingreso masivo de las mujeres al universo laboral. Pero estos rasgos no reproducen la dinámica del pasado. El trabajo tiende actualmente a fragmentarse, rompiendo la uniformidad que prevaleció durante el taylorismo. Una nueva brecha separa a los ocupados de los desempleados y a los trabajadores estables de los precarios.

El trabajo informal se ha expandido junto a su contraparte intelectual. La hipótesis de taylorización uniforme choca con la multiplicación de tareas, que requieren mayor comprensión de la actividad realizada.

Incluso ciertos aspectos de la polivalencia exigen reintegrar el trabajo dividido y afectan al viejo modelo de prescripción estricta de tareas. Un nuevo tipo de actividades no taylorizadas aumenta junto a la extensión del trabajo degradado. Son dos procesos conjuntos que intelectualizan ciertas tareas y brutalizan otras.

Ambas tendencias han sido alimentadas por la revolución informática, que exige mayor compromiso mental de un segmento de trabajadores y creciente sometimiento de los involucrados en la fabricación estandarizada. Las corporaciones obtienen sus ganancias de una mixtura de ambos procesos, que la teoría del control patronal no registra en forma adecuada.

Es cierto que el capitalismo siempre recurrió a la segmentación laboral. Pero la polarización contemporánea supera todos los precedentes, se verifica en más países y orienta la gestión global de las empresas transnacionales. Esta segmentación permite a un puñado de economías patentar el $95 \%$ de los nuevos productos, monopolizar la actividad científica de punta y acaparar el grueso del trabajo intelectualizado. En la vereda opuesta se ubican las naciones, que compiten en el ofrecimiento de mano de obra barata para la fabricación en serie (ANTUNES, 1995; 1998-99; CASTELLS, 1996; GORDON, EDWARDS y REICH, 1985; DORE, 1992; LINHART, 1990-91).

Esta combinación entre mayor taylorización de actividades básicas y creciente intelectualización de tareas complejas genera un tipo de contradicciones, que tampoco son capturadas por la tesis del control patronal. Los empresarios necesitan mayor cooperación por parte de los trabajadores, pero al mismo tiempo desconfían de cualquier transferencia de conocimientos que permita mejorar los sueldos o las condiciones de trabajo.

El capitalismo no puede resolver este conflicto, ni tampoco optimizar el uso de las nuevas tecnologías que requieren circulación transparente de la información. El empresario necesita desenvolver, manipular y retraer al mismo tiempo este recurso, para asegurar su control del proceso de trabajo. Esta tensión entre socialización y mercantilización de la información ha creado serias dificultades en la gestión de la empresa, ya que exige optimizar la capacidad creativa y no sólo maximizar cierto rendimiento. Este aprovechamiento a su vez requiere la cooperación de trabajadores, que son sometidos a un sacrificio laboral cotidiano.

Frente al incremento de la dimensión intelectual del proceso productivo, los capitalistas deben reconciliar dos objetivos en conflicto: aumentar la rentabilidad a costa de los trabajadores y lograr su apoyo contra los 
concurrentes. También esta combinación de despotismo y colaboración enfrenta obstáculos insalvables (KATZ, 1998; 1999; CIBORRA, 1988; LOJKINE, 1998; COUTROT, 1998).

El discurso esquizofrénico que propaga la clase dominante expresa esta contradicción. Los capitalistas necesitan más cooperación, iniciativa personal y creatividad entre empleados, que son sometidos a creciente disciplina y opresión. Las tesis de Braverman describen esta tensión, pero no permiten comprender plenamente la dinámica de los conflictos en juego.

\section{Aciertos y Cuestionamientos}

La teoría del control patronal plantea una crítica demoledora a la sociología laboral tradicional, que niega la existencia de relaciones de explotación bajo el capitalismo. Esta concepción se basa en el pensamiento económico neoclásico y supone que el trabajador elige dónde y cómo trabajar, renunciando al ocio cuándo el salario prometido satisface sus aspiraciones. El mismo enfoque imagina también, que el asalariado obtiene ingresos equivalentes a su productividad y transmite espontáneamente sus conocimientos a la empresa, en cumplimiento de un contrato libremente acordado con los empleadores.

En esta visión la armonía laboral no enfrenta ningún trastorno, si el mercado opera en forma irrestricta, orientando las decisiones que optimizan los intereses comunes de empresarios y asalariados. Naturalmente los partidarios de esta mirada proclaman que las nociones de explotación o control patronal del trabajo han perdido actualidad (KERN y SCHUMANN, 1988).

Pero este encubrimiento del despotismo capitalista conduce a perder todo contacto con la realidad. En los hechos, el mercado no gestiona directamente la vida laboral. Las clases dominantes invariablemente recurren a la intervención estatal para organizar el trabajo, con el auxilio de una legislación laboral que disciplina a los asalariados.

Los exponentes de la ortodoxia presentan la tiranía del empresario como una cesión voluntaria de derechos. Interpretan que el asalariado delega en el capitalista la atribución de decidir cómo se trabaja, olvidando el carácter escandalosamente asimétrico de esa negociación.

Desde otra vereda, la heterodoxia trata estos problemas con mayor seriedad. Algunos autores aceptan incluso ciertos rasgos de la teoría del control patronal, aunque sin el alcance que le asignó Braverman. Afirman que el taylorismo constituye una modalidad de gestión laboral, en coexistencia con esquemas posfordistas y toyotistas y variadas opciones de otro tipo (MONTERO, 1986; 1989; ROJAS, 1990).

Efectivamente existen evidencias de esta multiplicidad. Pero Braverman no se limitó a defender la universalidad del taylorismo. Estudió una tendencia al dominio patronal del proceso de trabajo, que se fundamenta en la extracción capitalista de la plusvalía.

La gran mayoría de los analistas tienden a eludir esta caracterización y se limitan a postular la existencia de variadas situaciones no tayloristas. Remarcan que Braverman exageró el alcance de la "organización científica del trabajo", pero olvidan que acertó en subrayar la conexión de ese modelo con la lógica confiscatoria del régimen social vigente. Los críticos sugieren que esa norma de explotación no es inexorable bajo el capitalismo y cuestionan este núcleo de la teoría del control patronal. El problema radica en esta objeción y no sólo en el rechazo a presentación abusiva del taylorismo.

La tesis de Braverman destaca acertadamente como la explotación condiciona cualquier actividad laboral. Demuestra que este campo no es un universo de "múltiples posibilidades". Allí se imponen reglas de supremacía patronal para garantizar la extracción de plusvalía. Muchos críticos olvidan o diluyen este principio básico. 


\section{Lucha de Clases}

Al concentrar el análisis en las estrategias gerenciales: ¿la teoría del control patronal no ignora la subjetividad de los trabajadores y su resistencia contra el taylorismo? ¿No es Braverman víctima de la ideología que criticó, al tratar a la clase obrera como un objeto pasivo manipulado por los patrones?

Los autores que plantean este cuestionamiento destacan la importancia de registrar cómo los trabajadores lucharon y derrotaron al taylorismo. Braverman respondió que su análisis resalta el significado genérico de ese modelo y defendió la conveniencia de separar el análisis conceptual de la evolución concreta del taylorismo (EDWARDS, 1984; SMITH, 1995-96; BRAVERMAN, 1976).

En realidad el pensador estadounidense incluyó de hecho cierto contexto de lucha social. No ofreció una mirada puramente abstracta, ya que no se puede tratar la actividad laboral en los mismos términos que se indaga la teoría del valor o a los esquemas de la reproducción ampliada. Pero al omitir cuál fue la recepción concreta de la "gerencia científica" entre los trabajadores dejó abiertas muchas preguntas.

La teoría de Braverman no ignora la lucha de clases, puesto que ilustra cómo el capitalista recurre a sistemáticas agresiones para afianzar su dominio. Tampoco reduce a la clase obrera a un "simple instrumento", pero al omitir juicios sobre el resultado de estos atropellos sugiere que el taylorismo se impuso sin afrontar grandes obstáculos.

Estudios posteriores inspirados en la teoría del control patronal han incorporado más claramente la confrontación clasista. Noble analizó la lucha obrera por la defensa de la programación directa de las máquinas herramientas, frente a la presión gerencial por introducir un manejo centralizado. Shaiken describió batallas en las plantas automotrices, que sucesivamente concluyeron con imposiciones patronales y reapropiaciones obreras del control del trabajo. Grzyb ilustró cómo la tendencia a romper la cooperación informal de los trabajadores condujo periódicamente al resultado opuesto (NOBLE, 1987; 1984; SHAIKEN, 1981; 1991; GRZYB, 1988).

\section{Consentimiento y Subjetividad}

Algunos críticos destacan que Braverman ignoró el consentimiento que brindan los asalariados a las prácticas patronales, por medio de compromisos implícitos en torno a la intensidad del trabajo. Sostienen que a través estos acuerdos los obreros asumen los objetivos de la gerencia, adoptan comportamientos individualistas, olvidan la opresión y reivindican los éxitos de la empresa. Estiman que por esa vía los capitalistas logran la convalidación subjetiva y la legitimación ideológica de su acción (BUROWAY, 1989).

Esta objeción llama la atención sobre otro problema de la teoría del control patronal. Pero la insuficiencia se corrige incorporando al análisis la omitida secuencia de luchas políticas y sindicales. Con esa inclusión se puede registrar de qué forma repercuten las orientaciones gerenciales sobre la subjetividad colectiva, evaluando el impacto de este proceso sobre la organización y la conciencia de los trabajadores. Este es el camino para caracterizar qué grado de consentimiento brindan los asalariados a su condición de explotados.

La teoría del control patronal aporta un marco objetivo para analizar un consentimiento necesariamente cambiante. Esta conformidad no constituye un rasgo intrínseco de la acumulación, ni representa un comportamiento espontáneo de los trabajadores. Por eso resulta difícil distinguirlo de la resistencia silenciosa, la impotencia o la resignación.

Es indudable que los capitalistas buscan el favor de los trabajadores para asegurar el éxito de sus negocios. Pero la norma de la explotación y la preeminencia de la competencia impiden mantener un status de cooperación. La teoría de Braverman resalta esta tensión entre patrones y asalariados y recuerda que la convivencia entre explotadores y explotados no se establece en una relación entre pares. En el terreno laboral 
prevalece una forma de coerción, que limita cualquier consenso real entre los empleados y los dueños de la firma.

El propio análisis del consentimiento plantea complejos problemas, ya que resulta muy difícil probarlo en el terreno empírico. Las encuestas individuales suelen analizar percepciones de labores (gratificantes, angustiosas, estimulantes), omitiendo el contexto objetivo (trabajo fragmentado, homogéneo, rutinario o intelectualizado) y subjetivo (rebeldía, resistencia pasiva, sometimiento). Sólo un encuadre político-social permite evitar esas distorsiones.

Muchos estudios de la sociología ignoran ese contexto o tienden a privilegiar el análisis de las conductas individuales en desmedro del comportamiento colectivo. Enfatizan la problemática weberiana del status, ignorando el carácter capitalista de las relaciones laborales. En vez de indagar primero cómo y por qué dominan los patrones se limitan a registrar las formas de adaptación a esa opresión. Este enfoque predomina, especialmente, en la contraposición corriente entre consenso posfordista y autoritarismo taylorista.

\section{El Proceso de Valorización Relegado}

La teoría del control patronal ha sido actualizada por numerosos estudios. Estos enfoques resaltan el enmascaramiento de la explotación, en círculos de calidad que recrean la jerarquía disciplinaria o en métodos just in time, que aceleran el ritmo del trabajo (MARTÍNEZ, 1998; YATES, 1999; SMITH, 1995; 1989).

Estas investigaciones confirman la continuidad de muchos rasgos de la "gerencia científica" pero no confirman la supremacía del viejo taylorismo. Ese modelo no sólo choca con la expansión del trabajo intelectualizado. También vulnera las peculiaridades de la mercancía fuerza de trabajo, cuyo valor combina componentes fisiológicos con factores histórico-sociales (educación, conquistas, consumos).

Al pretender transformar al operario en una prolongación de la máquina, la brutalidad taylorista avasalla esos componentes. Enfrenta, además, la imposibilidad de sostener aumentos de la productividad, ya que el maltrato extremo de los trabajadores conduce al síndrome de la esclavitud. El látigo genera desinterés y la repetición de tareas incrementa los desperfectos o los desperdicios.

El taylorismo tiene decreciente funcionalidad para el uso de equipos complejos, ya que incentiva una falta de predisposición laboral que afecta el cuidado de los instrumentos. El fraccionamiento de tareas genera, además, obstáculos técnicos cuándo se debe optimizar la actividad en procesos continuos.

Algunos seguidores de Braverman no registran estas limitaciones. Pierden de vista que el control patronal se convierte en un obstáculo, para el empresario que busca motivar al trabajador. Esta contradicción es irresoluble bajo el capitalismo, pero el taylorismo es particularmente inadecuado para atenuarla. La tesis del control patronal no detecta que el patrón necesita capturar una "plusvalía subjetiva" (ingenio, creatividad, esfuerzo intelectual), que el mismo empresario socava al atropellar las identidades profesionales.

El modelo de Braverman no estudia estas contradicciones. Tampoco indaga cómo los capitalistas intentan resolverlas, segmentando la actividad laboral y rodeando la plantilla estable de trabajadores calificados con una masa de asalariados flexibilizados.

Estas dificultades analíticas derivan de un divorcio del proceso de trabajo de su determinante en la dinámica de la valorización. El pensador norteamericano presentó acertadamente su teoría, como un efecto de la compulsión a incrementar la tasa de beneficio. Pero terminó indagando la problemática del control sin correlacionarla con las tendencias de la acumulación.

Este enfoque implicó un deslizamiento de la interpretación económica de la plusvalía hacia el estudio político de las formas gerenciales. Por ese camino no observó que el centro del capitalismo es la explotación y no el control. Se introdujo dentro de la fábrica para estudiar todos los matices del proceso de trabajo y 
olvidó el condicionamiento general que impone la reproducción del capital (COHEN, 1987; CARCHEDI, 1991; HARVEY, 1990; ROWLINSON y HASSARD, 1994).

\section{El Planteo Recalificador}

Braverman propuso un criterio social para evaluar las calificaciones, en función del grado de comprensión que mantiene el trabajador de la tarea realizada. Se opuso al criterio de ingeniero, que sólo toma en cuenta la complejidad de las máquinas o el nivel educativo del operario.

Su enfoque apuntó a cuestionar las miradas fetichistas, que evalúan el acto humano del trabajo en función de la sofisticación de los artefactos. También resaltó el carácter ficticio de las categorías que habitualmente utiliza la sociología laboral (operario calificado, semi-calificado, no calificado). Estos conceptos omiten definir cuál es el grado real de dominio que detenta cada subgrupo de su actividad.

La visión de Braverman tiene gran actualidad frente a quiénes postulan la existencia de un proceso espontáneo de capacitación de los trabajadores. Los partidarios de ese enfoque consideran que la pérdida de calificaciones sólo predominó en los albores del capitalismo. Estiman que la competencia posterior ha potenciado la necesidad de operarios preparados para enfrentar situaciones aleatorias, con creciente calificación incorporada en forma tácita durante la vida laboral. Con esta visión plantean que el aumento de las calificaciones se expresa en las mejoras del nivel educativo (WOOD y BRYN, 1984; ADLER, 1987; CASTELLS, 1992; HIRSCHHORN, 1991; RUFFIER, 1986; VELTZ, 1986).

Estos enfoques predominan en muchas caracterizaciones elogiosas de la era pos-industrial o posfordista, pero su expresión tradicional es la teoría neoclásica del capital humano. Esta concepción atribuye los aumentos de la productividad a un aporte creciente del "factor trabajo", que es enriquecido por la ascendente incidencia del "insumo educativo".

Pero la complejidad de la producción y el incremento de la formación de los trabajadores, no se traducen automáticamente en una mayor calificación. Todo depende de la tarea realizada y de la comprensión de su contenido. Los ejemplos de graduados universitarios contratados para desenvolver actividades de baja jerarquía o de operarios, que manejan máquinas auto-programadas (sin comprender lo que están haciendo), refutan esa visión. La asociación directa entre mayor escolaridad y complejidad laboral no resuelve ninguna controversia sobre las calificaciones.

La conexión efectiva entre el nivel educativo y la actividad laboral está mediada por un conjunto de condiciones (mercado, profesión en juego, tipos de actividad, ubicación del país en el mercado mundial). El ciclo capitalista determina la intensidad de las demandas laborales y los cambios en la acumulación definen cuáles son las especialidades que despuntan o son desplazadas. Esta combinación no se manifiesta en una equiparación automática de la escolaridad con la jerarquía laboral.

El criterio social de calificaciones que propuso Braverman justamente evita esas correlaciones ingenuas entre educación y complejidad de las tareas, al subrayar la gravitación del dominio que detenta el trabajador sobre la actividad que realiza.

Los ejemplos que habitualmente presentan los teóricos de la recalificación se basan en extrapolaciones de ciertos rasgos del sector intelectualizado del trabajo al conjunto del universo laboral. De esa generalización surge la engañosa imagen de un masivo aumento de la calificación, que simplemente ignora la degradación predominante en los sectores flexibilizados.

Si la recalificación fuera una tendencia tan manifiesta debería expresarse en el valor efectivo de la fuerza de trabajo, es decir en los salarios y no sólo en el plano potencial de una capacitación mayor. El estancamiento salarial en las últimas dos décadas desmiente categóricamente ese curso. 
La tesis de la recalificación cierra los ojos ante una polarización dominante, que permitió a los capitalistas amalgamar complejidad del proceso productivo con elevados niveles de explotación. Esta segmentación ha sido empíricamente corroborada por numerosos estudios que retratan la combinación entre complejidad y banalidad laboral, que acompaña a la generalización de la informática (FREYSSENET, 1990; 1992; TRESSAC, SOUBIE y NEVEU, 1988; KAPLINSKY, 1987; KELLY, 1988; BESSANT y CHISHOLM, 1991).

Frente a las dificultades que plantean estos problemas, algunos enfoques optan por eludir la definición de algún rumbo de la calificación. Afirman que esa variable simplemente depende del modelo laboral prevaleciente (WILKINSON, 1984; ROJAS, 1990). Pero la variedad de opciones que presentan es muy numerosa y resulta imposible deducir alguna conclusión de sus caracterizaciones. A lo sumo se confirmaría, en forma tautológica, que la calificación asciende en ciertos países y ramas y en retrocede otros.

\section{Descalificación Absoluta}

De la preeminencia atribuida a la taylorización, Braverman dedujo un pronóstico de descalificación absoluta del trabajo. Estimó que el capitalismo tiende a "lobotomizar" el cerebro de los trabajadores. Sin compartir estos extremos, algunos autores aceptan esa visión. Consideran que la flexibilización laboral en curso reduce por completo las calificaciones y que la polivalencia disuelve totalmente las especialidades (BRAVERMAN, 1983; MARTÍNEZ, 1998; SMITH, 1995).

Esta mirada se nutre a veces de estudios empíricos que retratan la descalificación generada por la introducción de la informática en el proceso productivo. Presenta distintos ejemplos de conversión de sujetos pensantes, en autómatas sometidos a la rutina de las computadoras, en un contexto de expansión de las "burguer-actividades".

Otros analistas relativizan este aspecto de la teoría de Braverman y diferencian el análisis de la descalificación del estudio de la degradación del trabajo. Consideran que este último concepto sólo alude a la segmentación de las tareas y al mayor control del trabajo (FOSTER, 1999; GREENBAUM, 1999).

Pero la experiencia de la polarización laboral indica que la descalificación absoluta sólo afecta a los sectores obreros más taylorizados. Trazando una analogía con la evolución del salario se podría estimar, que bajo el capitalismo contemporáneo la tendencia preeminente es hacia una descalificación relativa.

El salario oscila coyunturalmente con el ciclo, pero a largo plazo tiende a declinar en relación a la productividad o el beneficio. Con la mayor inversión en capital constante se reduce la remuneración a los trabajadores en proporción al producto de su trabajo. Este curso del salario relativo tiene su correlato en las calificaciones.

Estas últimas variables también oscilan con el ciclo y decrecen, en comparación al nuevo horizonte de conocimientos que genera cada oleada de innovaciones. Incluso cuando prevalecen tendencias favorables a la educación de los trabajadores, la mejora es inferior al conocimiento potencial abierto con las nuevas tecnologías. La frontera del saber se amplía más que la instrucción recibida. En esta desproporción se asienta el control patronal. Adoptando, por lo tanto, las categorías centrales de Braverman se puede deducir una tendencia hacia la descalificación relativa pero no absoluta del trabajo.

Es igualmente difícil captar la evolución promedio de las calificaciones, dada la coexistencia del empobrecimiento con el enriquecimiento en las distintas actividades. Pero si se reconoce que un sector de los asalariados mejora y otro no su comprensión de las tareas realizadas, la dinámica de la acumulación es coherente con cierta tendencia a la descalificación relativa. 
El concepto degradación absoluta que postuló Braverman impide captar este movimiento contradictorio hacia la devaluación y recomposición de las calificaciones. El teórico del control patronal acertó en afirmar, que una elevación genuina y permanente de las calificaciones requeriría la reorganización socialista de la economía. Pero se equivocó en suponer que este proceso estaría precedido por una degradación absoluta del trabajo.

Algunos autores atribuyen este desacierto a su omisión de un criterio que discrimine el trabajo material y mental. Estiman que el primer tipo de actividad implica transformar valores de uso y el segundo modificar los conocimientos existentes para transformar la realidad productiva. Destacan que ambos componentes pueden diferenciarse en función de las cualidades jerarquizadas en la demanda de cada producto (un libro por el aspecto mental y un zapato por el material). Puntualizan que todas las actividades productivas incluyen necesariamente los dos elementos de este trabajo colectivo, pero indican que en la línea de montaje prevalece la transformación material y en los laboratorios de investigación la conversión mental (CARCHEDI, 1991).

Tomando en cuenta estas distinciones resulta más indefendible el pronóstico de degradación absoluta, ya que sobran evidencias de ampliación del trabajo mental en el capitalismo contemporáneo. Es completamente imposible aplicar conocimientos existentes para crear nuevos conocimientos (y a su vez implementarlos para transformar valores de uso), en un contexto de total descalificación del trabajo. Esta degradación es también incompatible con la creciente demanda de mercancías por cualidades derivadas del trabajo mental.

\section{Miseria Creciente}

Braverman subrayó la significativa influencia de la ciencia sobre la producción que Marx denominaba trabajo general, Aceptó que la tasa de ganancia de los sectores más dinámicos depende de rentas tecnológicas, surgidas de este uso capitalista de la ciencia. Incluso interpretaba a esa aplicación como un componente central de la revolución científico-técnica del siglo XX.

Pero el pensador norteamericano consideraba que esa gravitación potenciaba el taylorismo, sin notar la intelectualización del trabajo que se requiere para transformar los nuevos descubrimientos en productos comerciales. Ciertamente esta calificación sólo involucra a un sector de los asalariados, pero la incidencia cuantitativa y la importancia estratégica de este segmento se torna vital con la expansión de la acumulación (VENCE, 1995; VINCENT, 1995; 1998).

El principal problema del enfoque de Braverman estriba en su pronóstico de "lobotomización" de los asalariados. Esta previsión tiene importantes consecuencias políticas, ya que abre un serio interrogante sobre la capacidad de la clase obrera para encabezar un proyecto de emancipación. Si los trabajadores soportan una degradación creciente tenderían a convertirse en una masa de miserables, sin fuerza para protagonizar una transformación social. No es coherente asignarle a la clase obrera un rol socialista dirigente y estimar al mismo tiempo, que ese sujeto se descompone en la lucha por su propia supervivencia. Esa visión transmite un fuerte escepticismo en el rol histórico de los trabajadores, a pesar de la defensa marxista que hizo Braverman de ese principio.

Los errores contenidos en la tesis de la degradación obrera están muy conectados con la teoría de la miseria creciente. Este planteo observa a la acumulación como un proceso de polarización extrema, entre una minoría de capitalistas y una mayoría de obreros empujados hacia la pobreza total.

Marx inicialmente concibió esa posibilidad pero luego polemizó con la "ley de bronce de los salarios", afirmando que la miseria extrema recae sobre los desocupados o marginales y no sobre la masa de los asalariados. La miseria creciente contradice también la necesidad que tiene el capitalismo de ampliar mercados y convertir a los explotados en clientes. El propio sistema se ve obligado a expandir la capacidad de consumo y a retribuir - en alguna escala - el mayor gasto físico-mental de la fuerza de trabajo (MANDEL, 1978a; ROSDOLSKY, 1979). 


\section{Temas de Actualidad}

La centralidad, opresión y emancipación del trabajo constituyen tres aspectos de la obra de Braverman que presentan gran actualidad, pero en un contexto muy diferente a su época. En los años 70 se discutía la intensificación del trabajo, mientras que en las últimas décadas se ha debatido la carencia este recurso. De la crítica al sufrimiento del trabajo se ha pasado a la angustia por la ausencia de puestos laborales.

En la época de Braverman se analizaba el drama del desempleo pero no el "fin del trabajo". La vigencia de su investigación justamente radica en la oposición frontal que presenta a todas las exageraciones sobre la desaparición de la actividad laboral. Estas previsiones simplemente olvidan que el trabajo es una condición de subsistencia de cualquier sociedad y constituye el fundamento del proceso de valorización en que se asienta el capitalismo. Leer a Braverman permite recordar que sin trabajo no hay generación de riquezas, ni reproducción de la vida social.

Es cierto que en las últimas dos décadas se ha desarrollado una revolución tecnológica que transformó el proceso productivo. Pero también en el pasado se registraron varias transformaciones de ese tipo, que modificaron las formas del trabajo sin extinguirlo. La tesis apocalíptica que anuncia la completa sustitución de la mano de obra por procesos automatizados, convierte el problema el socio-económico del desempleo en un subproducto de la tecnología. Supone que las máquinas expulsan mano de obra por su cuenta, omitiendo que esta acción es efectivizada por capitalistas y guiada por el principio de rentabilidad.

El aumento del desempleo obedece a la reconstitución de un ejército de desocupados, que ha presionado sobre el salario para permitir la recuperación de la tasa de ganancia. Esta lógica de la acumulación -en contextos demográficos, fases del ciclo y fuerzas político-sociales muy diversas- determina la tasa de desempleo. Son principios que rigen desde hace dos siglos y nunca condujeron al fin del trabajo.

Este pronóstico se ha transformado en una ideología que justifica los atropellos de las clases dominantes. Se proclama que la "era de la plena ocupación concluyó" y que la "tasa natural de desempleo debe subir". Pero el empleo se ha expandido en todos los sectores que han facilitado el aumento de la tasa de plusvalía (nueva periferia industrializada, mujeres, precarizados). Con el fantasma de la disolución laboral se enmascara la reorganización opresiva del trabajo que Braverman denunció reiteradamente.

El segundo aspecto de actualidad de su obra es la centralidad de la explotación. Esta relevancia salta a la vista con la secuela de atropellos que perpetró el neoliberalismo. La perversa combinación de sobre-trabajo entre los ocupados con sub-trabajo entre los desocupados es un nefasto resultado de esa agresión. La mixtura entre exceso y falta de trabajo es actualmente más dramática que en la época de Braverman, pero obedece a la misma tiranía de la explotación que indagó el estudioso del taylorismo.

La reducción de la jornada laboral que permitiría aliviar la intensidad del trabajo entre los ocupados distribuyendo el empleo resultante entre los desocupados- se ha discutido desde los años 70. Esa mejora fue parcialmente conquistada por medio de la lucha y también arrebatada durante las contraofensivas patronales.

Pero una diferencia con el pasado es la deformación que rodea a este reclamo, cuándo los empresarios distorsionan su utilización para convertirlo en un mecanismo flexibilización laboral. En este caso la disminución de las horas de trabajo es acompañada por reducciones salariales y modificaciones de las condiciones laborales. La batalla por disminuir la jornada en forma drástica, igualitaria, universal y sin modificar el salario tiene actualmente mayor importancia estratégica que en los años de Braverman. Es un medio para avanzar en la recomposición social de la clase trabajadora, facilitar conquistas y permitir la recuperación de la confianza política de los explotados.

Finalmente el texto de Braverman es una referencia para el desarrollo de un proyecto de emancipación del trabajo en la tradición socialista. Este programa implica la auto-realización del individuo, mediante la erradicación progresiva de la explotación a través de un proceso de des-alienación. 
Este planteo socialista es incompatible con la promocionada "liberación del trabajo" dentro del capitalismo, mediante una paulatina sustitución del trabajo por el tiempo libre. Estas propuestas embellecen la dramática regresión que sufren los trabajadores precarizados y omiten que en las últimas décadas aumentó el paro forzoso y no el tiempo de ocio libremente elegido. El desplazamiento del trabajo por el desempleo no introduce ningún aspecto emancipador en la vida social (HUSSON, 1995-96a; 1996b; 1998).

La crisis actual del trabajo obedece a la relación predominante entre capitalistas y asalariados y no a cierto tipo de oficio. Afecta la forma histórica de trabajo alienado y no la dimensión antropológica de la actividad laboral. Erradicar el carácter capitalista del trabajo persiste como un objetivo, en los mismos términos que planteó Braverman.

\section{Del Entusiasmo al Olvido: Un Legado}

"Trabajo y capital monopolista" gozó de una eufórica recepción inicial, posteriormente seguida de rechazos y olvidos. Este giro fue personificado por algunos teóricos de la Regulación que abandonaron la huella de Braverman. Especialmente Coriat comenzó estudiando los efectos del control patronal en Francia, pero concluyó contraponiendo variantes negativas de taylorismo (anglosajón y neoliberal) con distintas opciones positivas de pos-taylorismo (CORIAT, 1982a; 1982b; 1992).

Con ese enfoque comparativo se reivindica también el pos-fordismo sueco y alemán o el toyotismo japonés, destacando su conveniencia para la "nueva economía de la variedad". Los padecimientos que Braverman atribuía al capitalismo son exclusivamente localizados en los modelos que preservan la rémora taylorista. En estos análisis el control patronal es omitido, la explotación queda restringida a cierta política económica y la plusvalía es borrada de cualquier reflexión.

Esta pérdida de sentido crítico es un rasgo compartido por muchos sociólogos del trabajo que se distanciaron de Braverman. Optaron por una reflexión des-comprometida de distintas situaciones laborales y un abandono de las denuncias de la opresión. Los "expertos en temas laborales" se han ubicado en las antípodas de la actitud que adoptó el estudioso norteamericano. Evalúan procesos de trabajo como si estuvieran en un laboratorio de sustancias químicas y no en el centro de la apropiación empresaria del trabajo no remunerado.

La tarea de comparar modelos económicos en función de su perfil laboral se ha convertido en una importante preocupación post-Braverman. Pero el habitual contraste entre posfordismos, toyotismos y taylorismos empobrece el análisis y desconecta las tendencias objetivas de la valorización del capital de su efecto sobre el proceso de trabajo.

Resulta particularmente ingenua la creencia que cierta política laboral es la clave del éxito económico de un país, cómo si los alemanes eligieran ser posfordistas, los malayos tayloristas y los africanos pre-tayloristas. El abandono de la lógica del capital que guió el estudio de Braverman es la causa de esta simplificación.

El olvido que rodea a la teoría del control patronal se explica por el clima neoliberal de las últimas décadas. Pero incluso en ese contexto adverso, "Trabajo y Capital Monopolista" continuó provocando un fuerte impacto emocional entre todos sus lectores. El libro presenta una cruda descripción del tormento del trabajo, que genera la inmediata identificación de quienes han conocido ese sufrimiento. El texto refleja no sólo una intensa elaboración intelectual, sino también la evidente experiencia de un trabajador y el militante político.

Braverman perteneció a la generación de socialistas que se radicalizaron durante los años 30 y jugaron un papel protagónico en el desarrollo de la izquierda norteamericana Fue sindicalista y organizador de corrientes combativas durante los duros años del maccartismo, integró el Socialist Worker Party. En su madurez mantuvo una estrecha relación con la revista Monthly Review. 
El pensador norteamericano buscó en la elaboración intelectual respuestas a los dilemas políticos que enfrentó como militante. Estudió detenidamente el taylorismo para desenvolver argumentos contra la cogestión obrero-patronal. También intentó explicar los cambios operados en la clase obrera y las dificultades que enfrentaba la izquierda estadounidense. Braverman fue un intelectual socialista que integró la reflexión teórica con la experiencia militante. Escribió un libro clásico para su tiempo y adoptó una actitud que subsiste como modelo para todos los tiempos.

\section{Referencias}

ADLER, P. Automation et qualifications. Sociologie du Travail, Paris, n. 3, mars 1987.

ANTUNES, R. Adeus ao trabalho? São Paulo: Cortez editora, 1995.

La centralidad del trabajo hoy. Herramientas, n. 8, primavera/verano, 1998-99.

BARRIER LYNN, C. Notes en marge de celle de Jean Lojkine. Sociologie du Travail, Paris, n. 1, janvier 1983.

BESSANT, J.; CHISHOLM, A. Human factors in computer-integrated manufacturing. En: FORESTER, T. Computers in the human context. Cambridge: Cambridge University Press, 1991.

BRAVERMAN, Harry. Two comments. Monthly Review, n. 3, july/august 1976.

Trabajo y capital monopolista. México: Ed. Nuestro Tiempo, 1980.

La degradación del trabajo en el siglo XX. Monthly Review, n. 1, mayo 1983.

BUROWAY, M. El consentimiento en la producción. Ministerio de trabajo y Seguridad Social, Madrid, 1989.

CARCHEDI, G. Frontiers of political economy. London: Verso, 1991. Cap. 2.

CASTELLS, M. La informacionalización del trabajo. En: Socialismo del futuro. n. 6. Madrid: Fundación Sistema. 1992.

La era de la información. La sociedad red. Madrid: Alianza Editorial, 1996. v. 1.

CIBORRA, C. Intercambio, poder y coordinación: el debate sobre el desarrolo de la empresa. En: La automación y el futuro del trabajo. Ministerio de Seguridad Social, 1988.

COHEN, S. A labour process to nowhere? New Left Review, n. 165, p. 34-50, september 1987.

CORIAT, B. El taller y el cononómetro. Madrid: Siglo XXI, 1982.

Pensar al revés. México: Siglo XXI, 1992a.

El taller y el robot. México: Siglo XXI, 1992b.

COUTROT, T. L'éntreprise neoliberale: une hypothése feconde"? Congrés Marx International II, 30 septembre - 3 octobre 1998, Paris.

CHANDLER, A. La mano visible. La revolución en la direccide la empresa norteamericana, Colección historia social. Ministerio de Trabajo y Seguridad Social, Madrid, 1987.

DEJOURS, C. Entretien. Critique Comuniste, n. 152, eté 1998. 
DINA, A. Tecnología y trabajo: precedentes históricos y problemas actuales. En: La automación y el futuro del trabajo. Ministerio de Trabajo y Seguridad Social, Madrid, 1988.

DORE, R. La fábrica japonesa hoy: meditaciones de un evolucionista. Sociología del Trabajo, Madrid , n. 15, p. 31-62, primavera 1992.

DRUCKER, P. The new society of organizations. Harvard Business Review, september-october 1992.

EDWARDS, P. K. Homogenise, divide and rule: an essay on segmented work. Cambridge Journal of Economics, v. 8, n. 2, p. 197-215, 1984.

FOSTER, J. B. A classic of our times: labor and monopoly capital after a quarter-century. Monthly Review, v. 50, n. 8, p. 12-18, january 1999.

FREYSSENET, M. Dos formas sociales de automatización. Sociología del Trabajo, Madrid, n. 10, otoño 1990.

Processus et formes sociales. Sociologie du travail, Paris, n. 4, avril 1992.

; KOICHI, S. Toyota abandona el toyotismo. Realidad Económica, Buenos Aires, n. 154, febrero/marzo 1998.

GORDON, D. M.; EDWARDS, R.; REICH, J. M. Trabajo segmentado, trabajadores divididos. Ministerio de Trabajo y Seguridad Social, Madrid, 1985.

GREENBAUM, J. On twenty five years with Braverman's labor and monopoly capital. Monthly Review, v. 50, n. 8, p. 28-32, january 1999.

GRZYB, G. Descolectivización y recolectivizacien los lugares de trabajo. En: Las nuevas formas de organización del trabajo. Ministerio de Trabajo y Seguridad Social, 1988.

HARVEY, D. Los límites del capitalismo y la teoría marxista. México: Fondo de Cultura Económica, 1990.

HIRSCHHORN, L. Robots can't run ractories. En: FORESTER, T. Computers in the human context. Cambridge: Cambridge University Press, 1991.

HUNTER, M. Los asalariados y el tiempo. Le Monde Diplomatique, Enero 2000.

HUSSON, M. Fin du travail ou abolition du salariat? Critique Comuniste, n. 144, hiver 1995-96a. Misere du capital. Paris: Syros, 1996b. Cap. 3, 4, 6 y 8. . Communisme et temps libre. Critique Comuniste, n. 152, eté 1998.

KAPLINSKY, R. Microelectónica y empleo. Ministerio de Trabajo y Seguridad Social, Madrid, 1987. Cap. 5.

KATZ, C. Crisis y revolución tecnológica a fin de siglo. Realidad Económica, Buenos Aires, n. 154, febrero/marzo 1998.

Socialización y mercantilización de la información. Revista Ciclos, FCE-UBA, n. 17, primer semestre 1999.

. La teoría del control patronal: balance de una discusión. Revista Epoca, Buenos Aires, n. 2, p.171-203, 2000.

KELLY, J. Prácticas empresariales de reestructuración del trabajo. En: Las nuevas formas de organización del trabajo. Ministerio de Trabajo y Seguridad Social, Madrid, 1988.

KERN, H.; SCHUMANN, M. Trabajo y caracter social. En: La automación y el futuro del trabajo. Ministerio de Trabajo y Seguridad Social, Madrid, 1988. 
LAZONICK, W. et al. The labour process market strucutre and the marxist theory. Cambridge Journal of Economics, v. 3, n. 3, p. 227-230, 1979.

LINHART, D. Qué cambios en la empresa? Sociología del Trabajo, Madrid, n. 11, p. 25-48, invierno $1990-91$.

El trabajo y el empleo en Francia. Sociología del Trabajo, n. 31, p. 15-36, otoño 1997.

Entretrien. Critique Comuniste, n. 152, eté 1998.

LIPIETZ, A. Espejismos y milagros. Buenos Aires, 1992. Cap. 2, 4, 5.

LOJKINE, J. Entreprise et société. Paris: Puf, 1998. Intro, cap 1.

MANDEL, E. El capitalismo tardío. México: ERA, 1978. Cap. 8.

MARGLIN, S. What do bosses do? En: GORZ, A. Crítica de la división capitalista del trabajo, Madrid: Laia, 1977.

MARTINEZ, O. Los trabajadores frente a las nuevas formas de organización. Herramientas, Buenos Aires, n. 6, otoño 1998.

MILKMAN, R. El nuevo trabajo americano. Sociología del Trabajo, n. 31, p. 37-55, otoño 1997.

MONTERO, C. La sociologie de M. Buroway. Sociologie du Travail, Paris, n. 28, février 1986.

Cambio tecnológico, empleo y trabajo. Documento de Trabajo, Prealc, Santiago de Chile, n. 333, mayo 1989.

MONTGOMERY, D. El control obrero en Estados Unidos. Ministerio de Trabajo y Seguridad Social, Madrid, 1985.

NOBLE, D. Forces of production. A social history of machine tool automation. New York: A Konpf. 1984.

El diseno de Estados Unidos. Ministerio de Trabajo y Seguridad Social, Madrid, 1987.

PERRIN, J.; CANARON, J. Ciencia, tecnología y modos de organización del trabajo. En: Las nuevas formas de organización del trabajo, Ministrio de Trabajo y Seguridad Social, Madrid, 1988.

ROJAS, E. Nuevas tecnologías y acción sindical. Buenos Aires: Ed. Fundación Ebert, 1990.

ROSDOLSKY, R. Génesis y estructura de El Capital. Cap 3, pto 5. México: Siglo XXI, 1979. (Parte III, apéndice).

ROWLINSON, M.; HASSARD, J. Economics, politics, and labour process theory. Capital and Class, London , v. 18, n. 2, p. 65-97, Summer 1994.

RUFFIER, J. Taylorisier. Sociologie du Travail, Paris, janvier 1986.

SHAIKEN, H. Computadoras y relaciones de poder en la fábrica. Cuadernos Políticos, México, n. 30, p. 6-32, octubre 1981.

The automated factory. En: FORESTER, T. Computers in the human context, Cambridge: Cambridge University Press, 1991.

SMITH, T. Especialización. Sociología del trabajo, Madrid, n. 7, p. 35-62, 1989.

La production flexible: une utopie capitaliste? Cahier d'Etude et de recherche. Amsterdam, 1995.

SMITH, V. El legado de Braverman. La tradición del proceso de trabajo veinte años después. Sociología del trabajo, Madrid, n. 26, p. 3-28, Invierno 1995-96. 
TRESSAC, G.; SOUBIE, J. L.; NEVEU, J. P. Systemes experts et transferts d'expertise. Sociologie du Travail, Paris, n. 3, mars 1988.

VELTZ, P. Informatisation des industries manufacturieres et intelectualisation de la production. Sociologie du Travail, Paris, n. 1, janiver 1986.

VENCE, D. X. Economía de la innovación y del cambio tecnológico. Madrid: Siglo XXI, 1995.

VINCENT, J. M. Entrevista. El Rodaballo, n. 2, mayo 1995.

Entretien. Critique Comuniste, n. 152, eté 1998.

WILKINSON, B. Technologie, competence, et formation. Sociologie du Travail, Paris, n. 4, 1984.

WOOD, S.; BRYN, J. Qualifications tacites, division du travail. Sociologie du Travail, Paris, n. 4, avril 1984.

YATES, M. Braverman and the class struggle. Monthly Review, v. 50, n. 8, p. 2-11, january 1999. 